\title{
Omni-channel Service Operations: Building Technology-based Business Networks
}

\author{
João Reis \\ Department of Economics, Management and Industrial \\ Engineering and Tourism, Aveiro University \\ Aveiro, Portugal \\ reis.joao@ua.pt
}

\author{
Marlene Amorim \\ Department of Economics, Management and Industrial \\ Engineering and Tourism and GOVCOPP \\ Aveiro University \\ Aveiro, Portugal \\ mamorim@ua.pt \\ Nuno Melão \\ Department of Management and CI\&DETS, School of \\ Technology and Management of Viseu \\ Polytechnic Institute of Viseu \\ Viseu, Portugal \\ nmelao@estgv.ipv.pt
}

\begin{abstract}
This article investigates how omni-channel services operations are building technology-based business networks. It uses a case study research, which includes multiple sources of data collection for triangulation purposes, to study a real-life phenomenon. The results suggest that omni-channel companies are changing their landscape to business networks, looking for competitive advantages over their rivals. But this move incorporates new challenges, as it requires a transition based on operations management to allow these firms to adapt their processes and channels, in order to be able to collaborate in a heterogeneous network of firms. Another possible solution is the integration of innovation technologies that are enabling the combination of firm capabilities to underpin collaborative relationships. Previous research also suggests that service operations management in an omni-channel services context is largely unaddressed, as this discipline is essential for the edification of technology-based business networks. Thereby, this article provides real-life statements and examples of firms that are moving their service operations into a business network paradigm. Subsequently, since omni-channel services are multidisciplinary in nature, these exploratory results represent a fruitful opportunity for future research to involve other disciplines than service operations.
\end{abstract}

Keywords-Omni-channel services; Business networks; Case study; Service operations; Innovation technologies

\section{INTRODUCTION}

The service sector is an important part of the global economy and is growing steadily, stimulated by diverse factors such as automation, electronics and information technology [1, 2]. Today, firms are also adopting new channels [3] as these networking technologies are leading to unprecedented levels of customer connection and empowerment [4]. For instance, financial services have been pioneers and partially responsible for the adoption of new service delivery models trough the implementation of virtual service [5]. The progressive adoption of technology interfaces to support customer interactions introduced profound changes in the operations of service delivery systems, that led to the establishment of an early tradition of multi-channel service delivery [6,7], where customers are allowed to combine interactions with service employees with face-to-screen service [8]. Furthermore, customers prefer a variety of channels options when they undertake the process of purchasing good and services $[9,10,11]$. Whereas multi-channel was in vogue in the last decade, we now observe a move to the so-called omni-channel movement [12]. But the omni-channel strategy is not the only competitive instrument. Recent work on competitiveness has also emphasized the importance of business networking, the evidence illustrates that those firms which do not cooperate reduce their ability to enter into exchange relationships [13] and lose the ability to share markets [14]. This paper seeks to contribute to the research on how omni-channel service operations are helping companies to build business networks based on technology. In the next section we review the literature and discuss the different concepts. Then, we describe the methodological approach, the study sample and the analysis approach. The following section discusses the empirical findings, by providing real-life statements and business network examples. Finally, we present the academic and managerial insights, limitations and future research.

\section{OMNI-CHANNEL SERVICE OPERATIONS}

The move from multi- to omni-channel [12] renews the need to define each term, by its complexity and span, as customers can move from a single contact point to a brand experience. The current literature provides very limited insights over these definitions, as further investigations are needed. Even so, we will try to provide a definition to each concept. Usually, a

978-1-5090-5847-1/17/\$31.00 @2017 IEEE. 